04;15

\title{
Высоковольтный импульсный источник для питания холодных плазменных струй
}

\author{
() С.И. Мошкунов, В.Ю. Хомич, Е.А. Шершунова \\ Институт электрофизики и электроэнергетики РАН, Санкт-Петербург, Россия \\ ฯ E-mail: eshershunova@gmail.com
}

Поступило в Редакцию 17 сентября 2018 г.

Проведено исследование параметров ряда высоковольтных твердотельных коммутаторов. На основании анализа их работы собран импульсный источник высокого напряжения размером $105 \times 260 \times 180 \mathrm{~mm}$ для питания холодных плазменных струй, работающий от сети переменного напряжения $220 \mathrm{~V}, 50 \mathrm{~Hz}$.

DOI: 10.21883/PJTF.2019.03.47270.17528

В последнее десятилетие быстрыми темпами развивается плазменная медицина. Многие научные группы уже показали эффективное использование неравновесной низкотемпературной плазмы за счет формирования OH- и NO-группы в плазме для коагуляции крови, дезинфекции и стерилизации поверхности, запуска иммунной реакции организма в борьбе с раковыми клетками $[1,2]$.

Как правило, источник холодной плазмы представляет собой плазмотрон, или „плазменный карандаш“ [3]. Из сопла „карандаша“ на объект выдувается плазменная струя, которая очень удобна и безопасна для биомедицинских точечных воздействий благодаря небольшой площади обработки и температуре до $40^{\circ} \mathrm{C}$ [4]. Ввиду компактности чаще всего для генерации таких струй используют маломощные резонансные источники напряжения синусоидальной формы с частотой в десятки килогерц [5,6], которое формируется высоковольтным трансформатором. Однако такой подход не позволяет оперативно изменять мощность, вкладываемую в разряд, тогда как применение прямоугольных импульсов, эффективно формируемых составными твердотельными коммутаторами, напротив, этому способствует. Генераторы на их основе позволят изменять как амплитуду, так и частоту выходного напряжения.

На рис. 1 представлена схема генерации высоковольтных импульсов и фотография собранного генератора. Принцип формирования импульсов основан на работе высоковольтных составных коммутаторов $S 1$ и $S 2$, набранных путем последовательного включения силовых транзисторов, по полумостовой схеме [7]. Необходимое количество транзисторов $n$ для сборки определялось как отношение блокируемого напряжения составного ключа $6 \mathrm{kV}$ к рабочему напряжению на отдельном транзисторе $V_{1}$, рассчитанному как $V_{c e s} / 1.2$, где $V_{c e s}-$ напряжение пробоя транзистора.

Для питания высоковольтного коммутатора (HVS) был собран источник постоянного напряжения на $6 \mathrm{kV}$ мощностью $100 \mathrm{~W}(6 \mathrm{kV}$ DC), построенный на базе полумостового инвертора (HBI - half bridge invertor), управляемого посредством широтно-импульсной модуляции (PWM - pulse width modulation), и умножителя напряжения (VM — voltage multiplier) [8]. Этот источник заряжает накопительный конденсатор $C$, емкость которого $(1.3 \mathrm{nF})$ много больше емкости нагрузки. Напряжение на накопительном конденсаторе можно регулировать в пределах 0-6 kV посредством переменного резистора.

В качестве транзисторов для составного коммутатора были испытаны МОП-транзисторы (транзисторы на основе структуры металл-оксид-полупроводник) и биполярные транзисторы с изолированным затвором (БТИЗ) производства фирм Infineon и STMicroelectronics в корпусах ТО-220 и ТО-247, обеспечивающие наносекундные времена переключения: 1) IPW60R045CP ( $V_{\text {ces }}=650 \mathrm{~V}$ и ток $I_{c e}$ до $\left.60 \mathrm{~A}\right)$; 2) IRFB20B60PDI $(600 \mathrm{~V}, 20 \mathrm{~A})$; 3) SPP17N80C3 (800 V, 17 A); 4) STW9N150 (1500 V, $8 \mathrm{~A})$; 5) IPP90R340C3 (900 V, $15 \mathrm{~A})$; 6) IRGPS40B120UD $(1200 \mathrm{~V}, 80 \mathrm{~A})$.

Была проведена экспериментальная оценка быстродействия транзисторов в зависимости от сопротивления в затворе $R$ при работе на емкостную нагрузку $115 \mathrm{pF}$. Быстродействие оценивалось по длительности тока через емкость по полувысоте (FWHM). Как видно из рис. 2, $a$, при сопротивлении в затворе $\sim$ до $3 \Omega$ все транзисторы ведут себя приблизительно одинаково, однако с его увеличением транзисторы, рассчитанные на большее напряжение: STW9N150 (1500 V) и IRGPS40B120UD $(1200 \mathrm{~V})$, уступают другим по быстродействию.

Для выбранных транзисторов также была проведена оценка мощности потерь. Суммарная мощность потерь $P_{l o s}{ }_{1}$ находилась как сумма статических потерь транзистора $P_{s t}$, определяющихся его током проводимости $I_{c e}$ и напряжением насыщения $V_{c e s}$, и динамических потерь $P_{d}$, включающих потери в затворе транзистора $P_{g}$, потери при переключениях $P_{s w}$ и потери, обусловленные разрядом выходной емкости транзистора $P_{\text {oss }}$.

Потери в затворе определялись зарядом емкости затвора как $P_{g}=Q_{g} V_{g} \cdot f / 2$, где $Q_{g}$ - заряд в затворе транзистора, $V_{g}$ - напряжение на затворе, $f$ - частота повторения импульсов. Потери при переключении рассчитывались по формуле $P_{s w}=\left(\tau_{o n}+\tau_{o f f}\right) V_{c e s} I_{c e} \cdot f / 2$, где $\tau_{o n}, \tau_{o f f}-$ времена переходных процессов транзисторов при $R=2 \Omega$. Потери при разряде выходной 


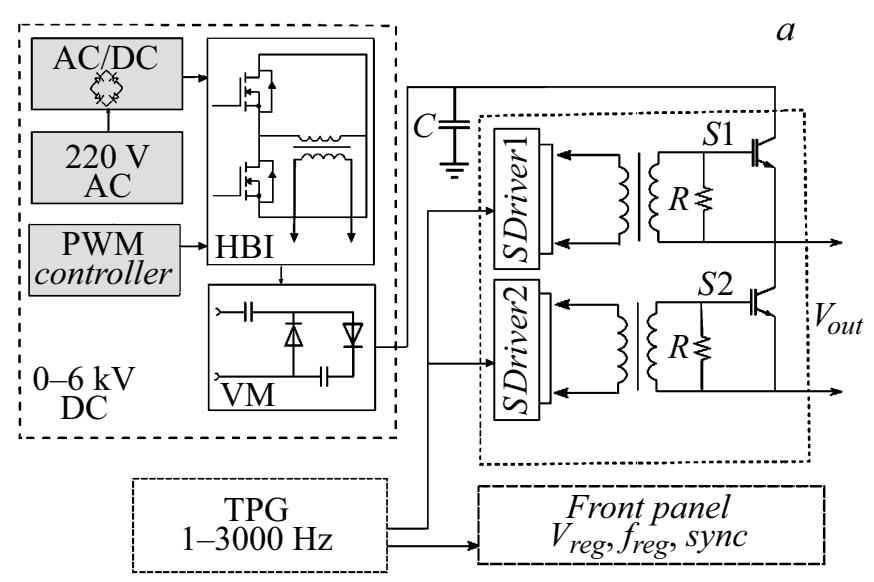

$b$

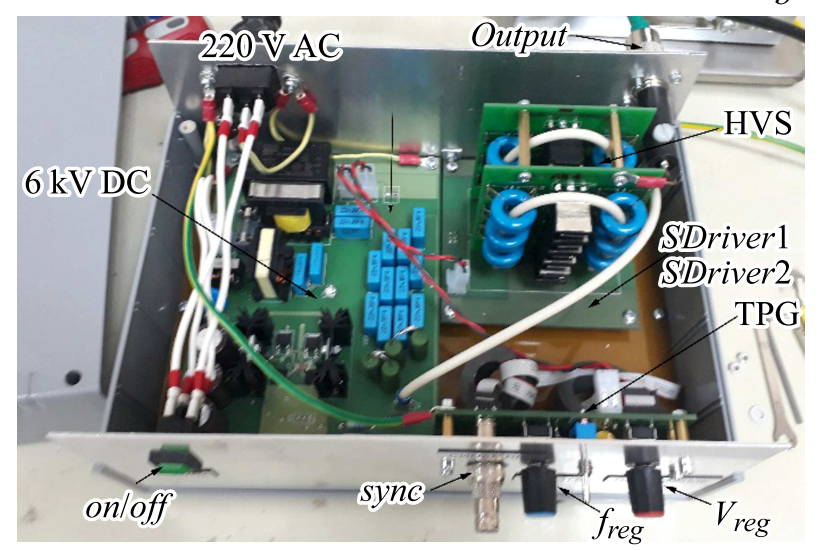

Рис. 1. $a-$ функциональная схема генератора, $b-$ фотография генератора импульсов (без верхней крышки).

емкости определялись как $P_{\text {oss }}=C_{o s s} V_{c e s} \cdot f / 2$. Полезная мощность транзистора находилась из выражения $P_{1}=V_{1} I_{c e} D$, где $D-$ коэффициент заполнения импульсов.

Мощности были рассчитаны при работе коммутатора на частоте $3 \mathrm{kHz}$ при длительности открытого состояния $500 \mathrm{~ns}$. Мощность потерь $6 \mathrm{kV}$-ключа $P_{\text {loss }}$ и его полезная мощность $P$ были найдены как $P_{\text {loss_1 }} n$ и $P_{1} n$ соответственно. Согласно расчетам (рис. $2, \bar{b}$ ), менее $10 \%$ теряется на коммутаторах из транзисторов моделей $1,3,5$ и 6 .

Ввиду высокой стойкости БТИЗ к короткому замыканию (в отличие от МОП-транзисторов) и их стабильной работы в полумостовой схеме выбор был сделан в пользу транзисторов модели 6 - IRGPS40B120UD, что также способствовало снижению габаритных размеров высоковольтного коммутатора благодаря высокому напряжению насыщения $1200 \mathrm{~V}$.

Управление транзисторными сборками было выполнено на отдельной плате, соосной с платой HVS (на фотографии находится под HVS, рис. $1, b)$. Плата управления включала два драйвера (SDriver 1, SDriver 2) для управления ключами $S 1$ и $S 2$ и была с ними галь- ванически развязана. За передней панелью генератора (front panel) была расположена плата генератора задающих импульсов (TPG). Она формирует прямоугольные импульсы требуемой длительности и частоты от 0 до $3000 \mathrm{~Hz}$ для формирования импульсов управления транзисторами в сборке, а также задержку между ними, определяющую длительность выходных высоковольтных импульсов. В основе работы TPG лежит использование $R C$-таймеров NE555 совместно с триггерами Шмитта.

На переднюю панель прибора (front panel) вынесен разъем синхронизации импульсов $(s y n c)$, ручки для регулировки частоты $\left(f_{\text {reg }}\right)$ и амплитуды напряжения $\left(V_{\text {reg }}\right)$. Сеть $(220 \mathrm{~V}$ АC), заземление и высоковольтный вывод (Output) находятся на задней панели.

При испытании генератора в качестве нагрузки был использован плазмотрон на базе барьерного разряда [9], выполненный в виде кварцевой трубки диаметром $5 \mathrm{~mm}$ с толщиной стенок $1 \mathrm{~mm}$. Медная проволока диаметром $2 \mathrm{~mm}$ использовалась в качестве высоковольтного электрода, медная фольга снаружи трубки - в качестве заземленного. Эффективная емкость нагрузки составляла $\sim 10 \mathrm{pF}$. Тестирование происходило без прокачки газоразрядного промежутка. Напряжение регистрировалось высоковольтным пробником Tektronix P6015A,
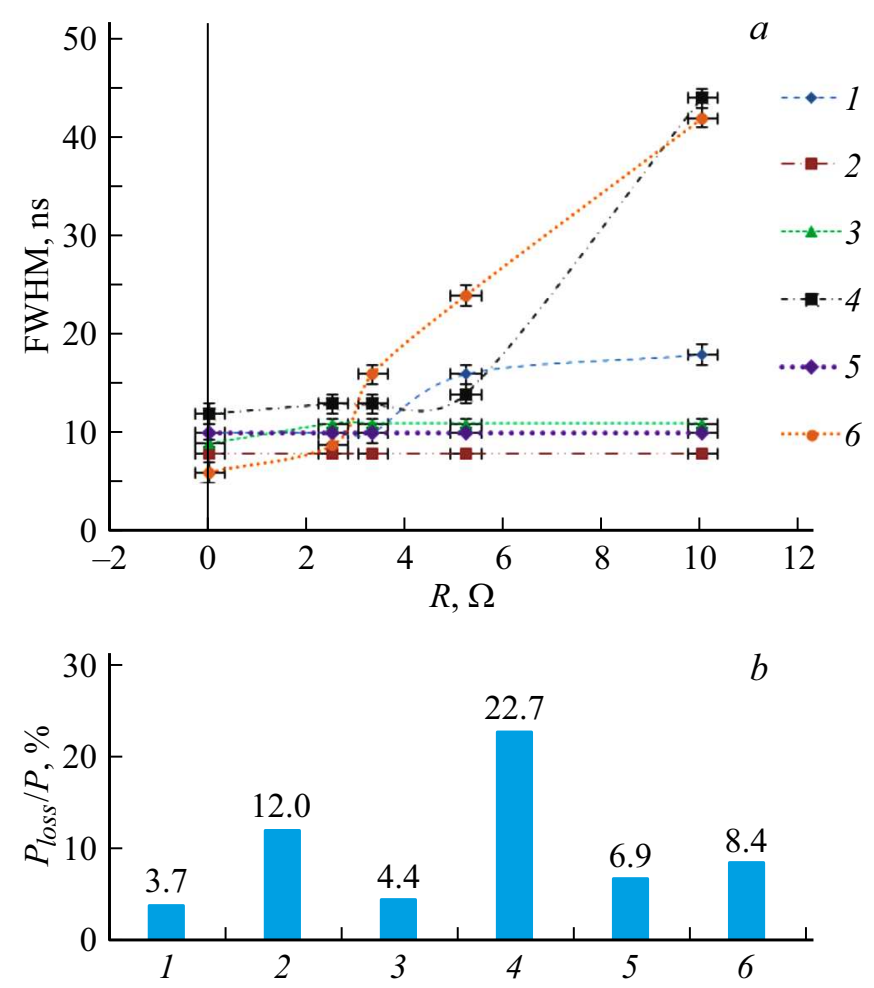

Рис. 2. Результаты исследования высоковольтных коммутаторов. $a-$ зависимость быстродействия (FWHM) транзисторов от сопротивления в затворе $R ; b$ - потери мощности в составных $6 \mathrm{kV}$-коммутаторах, набранных из транзисторов моделей 1-6. 1 - IPW60R045CP, 2 - IRFB20B60PDI, 3 - SPP17N80C3, 4 - STW9N150, 5 - IPP90R340C3, $6-$ IRGPS40B120UD. 


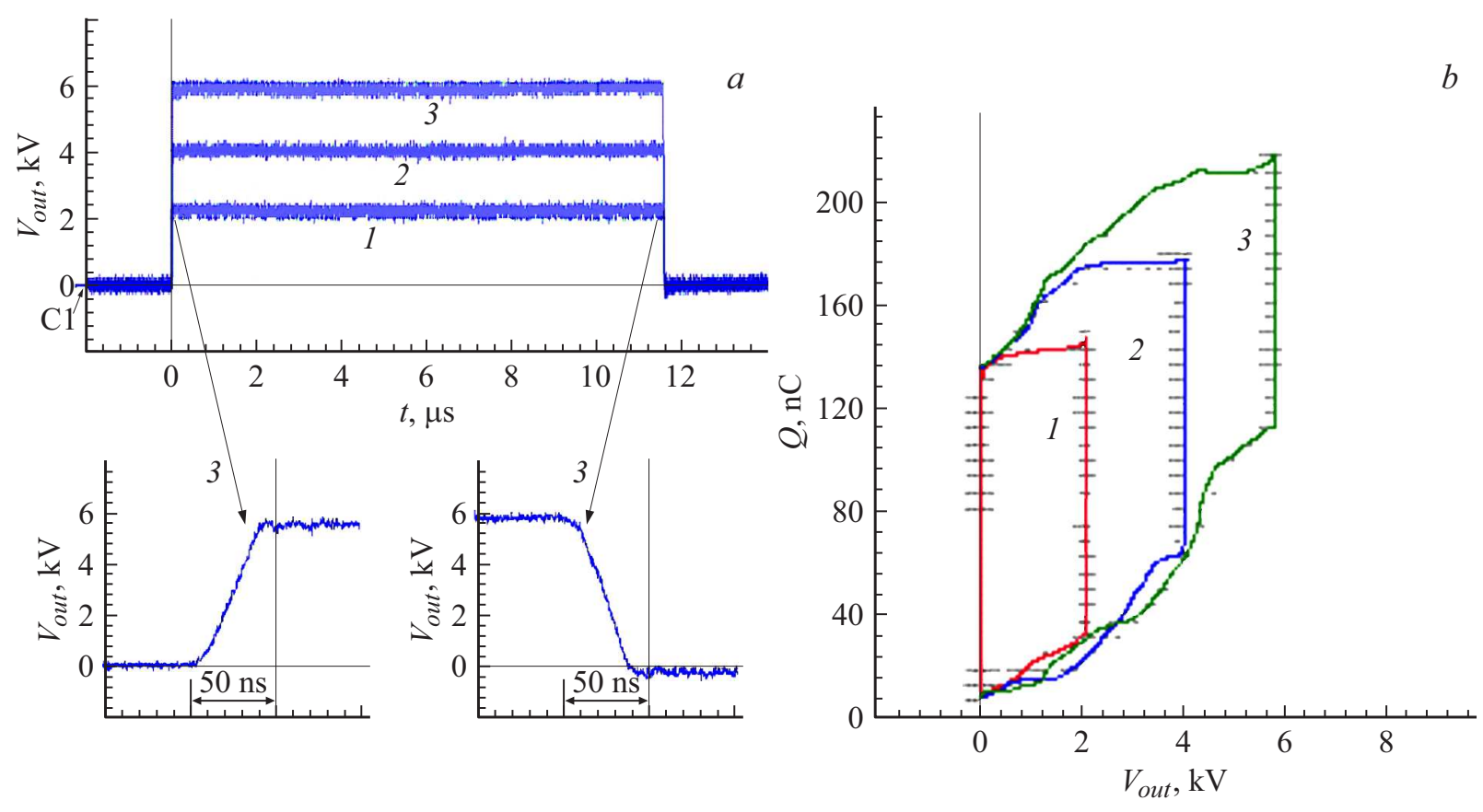

Рис. 3. Осциллограммы импульса напряжения $V_{\text {out }}$ на электродах плазмотрона $(a)$ и фигуры Лиссажу $(b)$ для трех амплитуд напряжения. $1-2 \mathrm{kV}, 2-4 \mathrm{kV}, 3-6 \mathrm{kV}$.

а ток - резистивным датчиком с коэффициентом $40 \mathrm{~A} / \mathrm{V}$.

Как видно из рис. 3, $a$, несмотря на нелинейность емкостной нагрузки, импульсы стабильны вне зависимости от амплитуды напряжения $V_{\text {out }}$ и имеют наносекундные времена нарастания $t_{r}$ и спада $t_{f}$. При $V_{\text {out }}=6 \mathrm{kV}$ $t_{r}=17.2 \pm 0.7 \mathrm{~ns}, t_{f}=24.3 \pm 0.6 \mathrm{~ns}$. По фигурам Лиссажу (рис. $3, b$ ) для $V_{\text {out }}=2,4$ и $6 \mathrm{kV}$ (отмечены цифрами 1-3) была посчитана энергия в импульсе. Установлено, что при $V_{\text {out }}=6 \mathrm{kV}$ энергия в импульсе составляет около $0.7 \mathrm{~mJ}$, а следовательно, средняя мощность при частоте $3 \mathrm{kHz}$ достигает около $2 \mathrm{~W}$.

Таким образом, разработан генератор, который в отличие от резонансного синусоидального источника напряжения может формировать прямоугольные импульсы регулируемой амплитуды и частоты с наносекундными временами нарастания и спада на нелинейную емкостную нагрузку с эквивалентной емкостью в единицыдесятки пикофарад.

Прибор достаточно компактен, отличается эргономичной конструкцией, имеет размеры $105 \times 260 \times 180 \mathrm{~mm}$ и питается от бытовой сети $220 \mathrm{~V}, 50 \mathrm{~Hz}$.

Его испытания в качестве источника питания воздушных плазменных струй доказали надежность и стабильность прибора и указывают на перспективность его использования для различных прикладных задач.

Работа выполнена при поддержке программы Президиума РАН № 31 на 2018-2020 гг.

\section{Список литературы}

[1] Weltmann K.D., von Woedtke T. // Plasma Phys. Control. Fusion. 2016. V. 59. N 1. P. 014031.

[2] Miller V., Lin A., Fridman A. // Plasma Chem. Plasma Process. 2016. V. 36. N 1. P. 259-268.

[3] Laroussi M. // IEEE Transact. Plasma Sci. 2015. V. 43. N 3. P. 703-712.

[4] Reuter S., von Woedtke T., Weltmann K.D. // J. Phys. D: Appl. Phys. 2018. V. 51. N 23. P. 233001.

[5] Lunov O., Zablotskii V., Churpita O., Chánová E., Syková E., Dejneka A., Kubinová Š. // Sci. Rep. 2014. V. 4. P. 7129.

[6] Xu N., Cui X., Fang Z., Shi Y., Zhou R. // IEEE Transact. Plasma Sci. 2018. V. 46. N 4. Pt 2. P. 947-953.

[7] Малашин М.В., Мошкунов С.И., Хомич В.Ю., Шериунова E.A. // Приборы и техника эксперимента. 2016. № 2. C. $71-75$.

[8] Мошкунов С.И., Хомич В.Ю., Шериунова Е.А. // Письма в ЖТФ. 2018. Т. 44. В. 2. С. 104-110.

[9] Lu X., Laroussi M., Puech V. // Plasma Sources Sci. Technol. 2012. V. 21. N 3. P. 034005. 